\title{
A survey on awareness among doctors on availability and usage of National Paediatric Guidelines in a district in Sri Lanka
}

\author{
T G P M Gamage ${ }^{1}$, S Rupasinghe ${ }^{2}$ \\ Sri Lanka Journal of Child Health, 2010; 39: 102-103
}

(Key words: National paediatric guidelines, awareness, Sri Lanka)

Introduction

Clinical guidelines are defined as systematically developed statements to assist both practitioner and patient decisions in specific circumstances ${ }^{1}$. They are viewed as useful tools in making care more consistent and efficient ${ }^{1}$. However, there is growing awareness that simply providing information may not lead to appropriate changes in health care practices ${ }^{2}$.

National Paediatric Guidelines (NPGs) were introduced to Sri Lanka in $2007^{3}$. NPGs comprise three volumes on different topics. To ensure optimal care of children, they were distributed to all hospitals in a printed format.

It is important to carry out an audit on the use of NPGs, especially in remote rural areas, where there is no access to relevant educational programmes.

\section{Objectives}

To describe the awareness of NPGs and adherence to them among doctors working in the government sector in Polonnaruwa district.

\section{Method}

This was a cross sectional descriptive study carried out in the Polonnaruwa district. A self administered questionnaire was distributed personally among all medical officers (including registered medical officers and assistant medical practitioners) involved in paediatric care in all government institutions in Polonnaruwa district.

${ }^{1}$ Acting Paediatrician, Medirigiriya, ${ }^{2}$ Paediatric Registrar, Lady Ridgeway hospital, Colombo

(Received on 7 July 2009. Accepted on 19 December 2009)

\section{Results}

Of the 82 medical officers who received questionnaires 70 responded. Twelve medical officers did not receive questionnaires as they were on leave at that time. Of the 70 responders, 17 were from General Hospital, 13 from Base Hospital, 12 from District Hospitals, 9 from Rural Hospitals, 4 from Peripheral Units, 4 from Central Dispensaries and 11 from the MOH Office. Forty nine had been in service for less than 5 years, 10 for 5-10 years and 11 for a period exceeding 10 years.

Thirty nine $(56 \%)$ medical officers were aware of NPGs whereas $31(44 \%)$ were unaware of them. Those 31 medical officers represented almost all the institutions including General Hospital.

NPGs were introduced in 2007. Of those who were aware of them, 21 medical officers came to know about them in 2007, 13 in 2008 and 5 in 2009. Only $17(43 \%)$ of the 39 medical officers were aware of the availability or unavailability of NPGs in their own institutions. Only 24 (34\%) medical officers made use of NPGs in treating paediatric patients.

Eleven medical officers encountered some problems when practising according to the guidelines. The problems included non availability of recommended drugs, laboratory facilities and medical equipment, and heavy work load. A few (10) medical officers gave suggestions to improve usage of NPGs which included increasing monitoring and investigation facilities, increasing the staff in paediatric wards, and carrying out awareness programmes.

\section{Conclusions}

- Fifty six percent were aware of the National Paediatric Guidelines.

- Thirty four percent made use of them in their clinical practice. 


\section{Limitations of the study}

- We could not gather information from 12 medical officers who were on leave during this period.

- We have not assessed the knowledge of those who use guidelines objectively.

- Data from medical officers of General Hospital where workshops and clinical meetings are held most of the time have not been compared with that of medical officers who work in other institutions.

\section{Recommendations}

- Awareness programmes on NPGs are important especially in remote areas.

- $\quad$ Further studies in other areas of the country must be carried out to assess the awareness and usage of the NPGs.

\section{Acknowledgements}

We thank Dr. Priyantha Athapaththu, RDHS, Polonnaruwa for giving his permission to conduct this study and Dr. U K A C Chandrakeerthi, Regional epidemiologist, Polonnaruwa for helping us in collecting data despite his busy work.

\section{References}

1. Eccles McMahon J. How to develop cost conscious guidelines. Health Technol Assess 2001; 5 (16): 1-69.

2. National Paediatric Guidelines, Ministry of Health, Sri Lanka.
3. Prior M, Guverin M, Grimmer Sommers K, J Eval. The effectiveness of clinical guidelines implementation strategies. A synthesis of system review finding. Clin Prac 2008; 14(5): 888-97.

4. Grimshaw JM, Thomas RE, MacLennan G, Fraser C, Ramsay CR, Vale L, et al. Effectiveness and efficiency of guidelines dissemination \& implementation strategies. Health Technol Assess 2004: 8 (6) 1-72.

5. Grimshaw JM, Thomas RE, MacLennan G, Fraser C, Ramsay CR, Vale L, et al. Toward evidence-based quality improvement. Evidence (and its limitation) of the effectiveness of guidelines dissemination and implementation strategies 1966-1998. J Gen Intern Med 2006; 21 Suppl 2:S14-20.

6. Barosi G. Strategies for dissemination and implementation of guidelines. Unit of epidemiology, IRCCSpoliclinicos, matto, Pavia, Italy.PMID 16752055

7. Challiet N, Dube E, Dugasm, Audibert F, Tourigny C, Fraser WD, et al. Evidence based strategies for implementing guidelines in Obstetrics' systematic review. Research centre of UHC, University of Montreal, Canada. 